\title{
Acidic oxidation of kraft lignin into aromatic monomers catalyzed by transition metal salts
}

\section{Journal Article}

\section{Author(s):}

Werhan, Holger; Mir, Joan Mora; Voitl, Tobias; Rudolf von Rohr, Philipp

Publication date:

2011-08

\section{Permanent link:}

https://doi.org/10.3929/ethz-b-000038534

\section{Rights / license:}

In Copyright - Non-Commercial Use Permitted

\section{Originally published in:}

Holzforschung 65(5), https://doi.org/10.1515/HF.2011.071 


\section{Acidic oxidation of kraft lignin into aromatic monomers catalyzed by transition metal salts}

\author{
Holger Werhan, Joan Mora Mir, Tobias Voitl and \\ Philipp Rudolf von Rohr* \\ Institute of Process Engineering, ETH Zürich, Zürich, \\ Switzerland \\ * Corresponding author. \\ Institute of Process Engineering, ETH Zürich, Sonneggstrasse 3, \\ CH-8092 Zürich, Switzerland \\ Phone: +41446324388 \\ Fax: +4144632 1325 \\ E-mail: vonrohr@ipe.mavt.ethz.ch
}

\begin{abstract}
As one of the three main components in woody biomass, lignin is an abundant but underused renewable raw material and carbon source. Owing to its aromatic structure and large availability as a by-product of pulping, its conversion into chemicals is highly attractive. In the present work, the oxidation of a softwood kraft lignin in acidic media was investigated in the presence of a homogeneous catalyst. The objective was to find a cheap but efficient catalyst for the depolymerization of kraft lignin into aromatic monomers. Different transition metal salts were screened and compared to phosphomolybdic acid, which was investigated in previous studies, and to experiments in sulfuric acid without additional catalyst. Vanillin and methyl vanillate were the main monomeric products detected by gas chromatography/mass spectrometry but their formation was only slightly increased by using transition metal salts (up to $6.28 \mathrm{wt} \%$ yield). However, the presence of iron or copper chloride resulted in fast formation kinetics and significant amounts of other monomeric products. In addition, an efficient fragmentation of the lignin molecule from a weight-average molecular weight of $3500 \mathrm{~g} \mathrm{~mol}^{-1}$ down to $500 \mathrm{~g} \mathrm{~mol}^{-1}$ was observed by sizeexclusion chromatography. The enhanced incorporation of oxygen into the reaction products in the presence of those catalysts was proven by Fourier transform infrared spectroscopy and the influence of the catalyst concentration was studied.
\end{abstract}

Keywords: kraft lignin; methanol; oxidation; oxygen; sizeexclusion chromatography (SEC), transition metal salt; vanillin; weight-average molecular weight $\left(\mathrm{M}_{\mathrm{w}}\right)$.

\section{Introduction}

Each year, roughly 70 million tonnes of lignin by-products arise in pulp mills during the production of pulp (Pye 2008).
More than $99 \%$ of the lignin from the kraft process is burned for the recovery of pulping chemicals and the provision of energy. Although modern kraft mills have an energy excess and kraft lignin can efficiently be precipitated from black liquor, only about 100000 tonnes of it are recovered and commercialized (Olsson et al. 2006; Tomani and Axegard 2007; Pye 2008). A large amount thereof is chemically modified by sulfonation, resulting in increased water solubility. Sulfonated kraft lignin competes with lignosulfonates obtained from sulfite pulping in some low-value applications as emulsifiers, surfactants, and dispersants, just to mention a few. However, the conversion of this cheap and renewable feedstock into aromatic building blocks would be very promising. Many different chemical transformations (e.g., hydrogenolysis, hydrolysis, oxidation) for the conversion of lignin into low molecular weight products are discussed in detail in the literature (Goheen 1981; Amen-Chen et al. 2001). A comprehensive review was recently published by Zakzeski et al. (2010) with the scope on catalytic chemical conversion of lignin and the chemical reactions involved in the processes. Among the reactions to produce low molecular weight products of lignin, the conversion of lignin into vanillin, in particular, was evaluated as being highly viable (Hermans et al. 2009).

While vanillin was commercially produced by alkaline oxidation of lignosulfonates in the 1980s at a yield of about $15 \%$ (Faith et al. 1965), environmental and economic reasons led to the closure of most of the production plants until today (Hocking 1997). In contrast to lignosulfonates, the alkaline oxidation of the by far more abundant kraft lignin is not suitable for yielding vanillin in reasonable amounts. Villar et al. (2001) reported a yield of $4 \%$ aldehydes (syringaldehyde and vanillin) for the conversion of a hardwood kraft lignin in $\mathrm{NaOH}$ solution with copper or cobalt salts as a catalyst.

In the present paper, the focus is on an alternative approach for the conversion of kraft lignin into vanillin and other functionalized phenols. It is based on the catalytic oxidation in acidic solvent of alcohols to prevent lignin fragments from undergoing condensation reactions (Voitl and Rudolf von Rohr 2008). The role of the homogeneous catalyst within the reaction is to promote cleavage of the bonds in kraft lignin during acidic oxidation with oxygen as oxidant, while simple alcohols proved to prevent condensation reactions of lignin fragments in acidic media (Voitl et al. 2009). The reaction is carried out in an acidic mixture of methanol and water at $170^{\circ} \mathrm{C}$ with an oxygen pressure of 10 bar. Monomeric reaction products detected by gas chromatography/mass spectrometry (GC/MS) are mainly vanillin and methyl vanillate. The latter is formed by acid-catalyzed esterification of vanillic acid in the presence of methanol and 
is not found in reactions carried out in pure water. In addition to the monomeric products, size-exclusion chromatography (SEC) analysis revealed significant amounts of dimeric/trimeric and oligomeric reaction products.

Different homogeneous catalysts are studied concerning their potential to depolymerize kraft lignin for the production of monomeric products. Voitl and Rudolf von Rohr (2008) have already demonstrated the potential of phosphomolybdic acid $\left(\mathrm{H}_{3} \mathrm{PMo}_{12} \mathrm{O}_{40}\right)$, which belongs to the group of polyoxometalates (POM), as a homogeneous catalyst. Wu et al. (1994) obtained up to $14.6 \%$ of aromatic aldehydes $(4.7 \%$ vanillin) from steam-explosion hardwood lignin with $\mathrm{CuSO}_{4}$ and $\mathrm{FeCl}_{3}$ catalysts in a $13.5 \% \mathrm{NaOH}$ solution. In the aforementioned studies of Villar et al. (2001), copper and cobalt salts served as homogeneous catalysts in $\mathrm{NaOH}$ solution. Up to $10.9 \%$ of aromatic aldehydes and aromatic acids were produced by oxidation of a hardwood organosolv lignin in acetic acid/water (Partenheimer 2009) with a $\mathrm{Co} / \mathrm{Mn} / \mathrm{Zr} / \mathrm{Br}$ catalyst. In the present study, the performance of different transition metal salts $\left(\mathrm{CuSO}_{4}, \mathrm{FeCl}_{3}, \mathrm{CuCl}_{2}, \mathrm{CoCl}_{2}\right)$ is investigated within the acidic oxidation of kraft lignin. Since the action of the catalyst is assumed to be based on its redox potential as reported for delignification studies (Gaspar et al. 2007), the transition metals are chosen to have a broad spectrum of cation redox potential $\left(\mathrm{Co} / \mathrm{Co}^{2+}=-0.28 \mathrm{~V}, \mathrm{Cu}^{+} / \mathrm{Cu}^{2+}=0.15 \mathrm{~V}\right.$, $\left.\mathrm{Fe}^{2+} / \mathrm{Fe}^{3+}=0.77 \mathrm{~V}\right)$. All of these values are below the redox potential of oxygen $\left(\mathrm{O}_{2} / \mathrm{H}_{2} \mathrm{O}=1.21 \mathrm{~V}\right)$, which is necessary for the reoxidation of the catalyst. The results of the catalyst experiments are compared to the reaction carried out in pure solvent acidified by sulfuric acid as well as to the results of previously performed experiments with phosphomolybdic acid.

\section{Materials and methods}

All batch experiments were performed in a $400 \mathrm{ml}$ high-pressure autoclave (Premex Reactor AG, Lengnau, Switzerland). The reactor is equipped with a gas entrainment impeller and its internal parts are made of titanium. For each experiment, the reaction solvent was prepared by mixing $160 \mathrm{ml}$ methanol and $40 \mathrm{ml}$ deionized water. Afterwards, the catalyst was added to the reaction solvent in an amount to give a concentration of $0.01 \mathrm{~mol} \mathrm{l}^{-1}$ and the $\mathrm{pH}$ was adjusted to $\mathrm{pH} 1.0$ by adding some droplets of concentrated sulfuric acid. All of the catalysts were completely dissolved in the reaction solvent. This mixture was then transferred into the reactor and $2 \mathrm{~g}$ of Indulin AT [kraft pine lignin, 97\% lignin content (dry), 5\% moisture, Mead Westvaco, Charleston, USA] were added, resulting in a nominal lignin concentration of $10 \mathrm{~g} \mathrm{l}^{-1}$. Indulin AT is well characterized and described in the literature (Ferraz et al. 1997; Beis et al. 2010). In experiments with vanillin or methyl vanillate as substrate, $150 \mathrm{mg}$ thereof was added to the reactor instead of Indulin AT. As kraft lignin is not soluble in acidic media, virtually all of the lignin was present as a solid/liquid suspension before the reaction. The reactor was sealed and purged three times by loading and releasing oxygen at a pressure of 10 bar. A working pressure of 10 bar oxygen was finally loaded to the reactor and the impeller was started at $1000 \mathrm{rpm}$. The mixture was heated to the reaction temperature of $170^{\circ} \mathrm{C}$ at a rate of $8 \mathrm{~K} \mathrm{~min}^{-1}$. When the reactor had reached the final temperature (defined as reaction time $t=0 \mathrm{~min}$ ), a liquid sample of approximately $8 \mathrm{ml}$ was drawn through a sampling tube, which was connected to a sampling valve at the top of the reactor. A heat exchanger connected to that valve allowed the quenching of the hot sample. Additional samples were taken every 20 min until a reaction time of $2 \mathrm{~h}$ was reached. Just before sampling, a liquid volume of about $17 \mathrm{ml}$ (corresponding to a volume slightly bigger than the dead volume of the sampling devices) was sampled and discarded. After the final reaction time was reached, the reactor was cooled to room temperature within $60 \mathrm{~min}$. The remaining reaction products were dissolved in the solvent, except for experiments with sulfuric acid and POM, where small amounts of finely dispersed solids were present.

Each sample was analyzed concerning its content of monomeric products by GC/MS. Five $\mathrm{ml}$ of each sample were taken and diluted with $2 \mathrm{ml}$ of water to inhibit miscibility with $\mathrm{CHCl}_{3}$, which was the solvent for extraction of the reaction products from the reaction mixture. The mixture was extracted three times with $3 \mathrm{ml} \mathrm{CHCl}_{3}$ and the organic phase was recovered. Then, $750 \mu$ l of a solution containing $1 \mathrm{~g} \mathrm{l}^{-1}$ syringaldehyde [as internal standard (IS) for quantification in $\mathrm{GC} / \mathrm{MS}$ analysis] in $\mathrm{CHCl}_{3}$ was added to the combined $\mathrm{CHCl}_{3}$ extracts. Syringaldehyde as IS is advantageous owing to its chemical similarity to vanillin and its high stability. In case of softwood lignins (e.g., Indulin AT), which contain only traces of syringyl units, the use of syringaldehyde as IS does not detract from the analysis. Split injections $(1 \mu 1)$ were done by an autosampler (Thermo Scientific, AI 3000, Waltham, MA, USA) into the GC/MS system (Thermo Scientific, Trace GC Ultra/Polaris ITQ ion trap, EI mode). The GC system was equipped with a Restek RTX-5 ms capillary column $(30 \mathrm{~m} \times 0.25 \mathrm{~mm} \times 0.25 \mu \mathrm{m})$ : carrier gas: $\mathrm{He}$ (flow of $1 \mathrm{ml} \mathrm{min}^{-1}$ ) with a split ratio of $25: 1$; temperature program: $80^{\circ} \mathrm{C}$ for $5 \mathrm{~min}$, heating by $10 \mathrm{~K} \mathrm{~min}^{-1}$ to $280^{\circ} \mathrm{C}$, and $280^{\circ} \mathrm{C}$ kept for $5 \mathrm{~min}$. Data presented are the average of two injections. The mean relative error between the GC/MS measurements was less than $5 \%$. The overall reproducibility of vanillin and methyl vanillate concentration was evaluated based on three experiments conducted with sulfuric acid in the absence of a catalyst. The maximum deviation of a measured concentration from the average value was always less than $7.1 \%$ for vanillin ( $8.6 \%$ for methyl vanillate), with an average value of $3.8 \%(4.9 \%)$.

For SEC, $2 \mathrm{ml}$ of each sample were adjusted to $\mathrm{pH} 12$ at a concentration of $2 \mathrm{~g} \mathrm{l}^{-1}$ by adding $\mathrm{NaOH}$ solution. A solution of Indulin AT was prepared with the same parameters as reference. All SEC samples were filtered before injection with nylon syringe filter (pore size $0.45 \mu \mathrm{m}$ ). The injection volume was $5 \mu \mathrm{l}$. Instruments and conditions used were as follows: Waters Alliance 2695 Separations Module; column cascade MCX $8 \times 300 \mathrm{~mm}(10 \mu \mathrm{m}) 1000 \AA$ and $100000 \AA$ plus precolumn (Polymer Standard Service GmbH, Germany); photodiode array detector (UV 210-400 nm); eluent $0.01 \mathrm{~N}$ $\mathrm{NaOH}$ solution. The eluent was prepared by means of FIXANAL ${ }^{\circledR}$ cartridges (Sigma Aldrich, Buchs, Switzerland) and stored under nitrogen sparging to avoid $\mathrm{CO}_{2}$ uptake. The flow rate was 0.5 $\mathrm{Ml} \mathrm{min}^{-1}$ and column temperature $35^{\circ} \mathrm{C}$. Detection of substances took place at $320 \mathrm{~nm}$. Calibration was between $697 \mathrm{~g} \mathrm{~mol}^{-1}$ and 148 $500 \mathrm{~g} \mathrm{~mol}^{-1}$ with poly(styrene sulfonate) sodium salt standards (PSS), and fitting was done by a third-order polynomial. Calibration below $697 \mathrm{~g} \mathrm{~mol}^{-1}$ : the four peaks with the longest elution times were assigned to be signals from products having one to four aromatic rings. This is especially true for vanillin, which eluates last in the chromatogram. A molar mass of $160 \mathrm{~g} \mathrm{~mol}^{-1}$ (close to vanillin) was assumed per aromatic ring in the products, resulting in $160 \mathrm{~g} \mathrm{~mol}^{-1}$ to $640 \mathrm{~g} \mathrm{~mol}^{-1}$ for monomers to tetramers. The thirdorder polynomial for fitting leads to a very good transition between the two calibration ranges. 


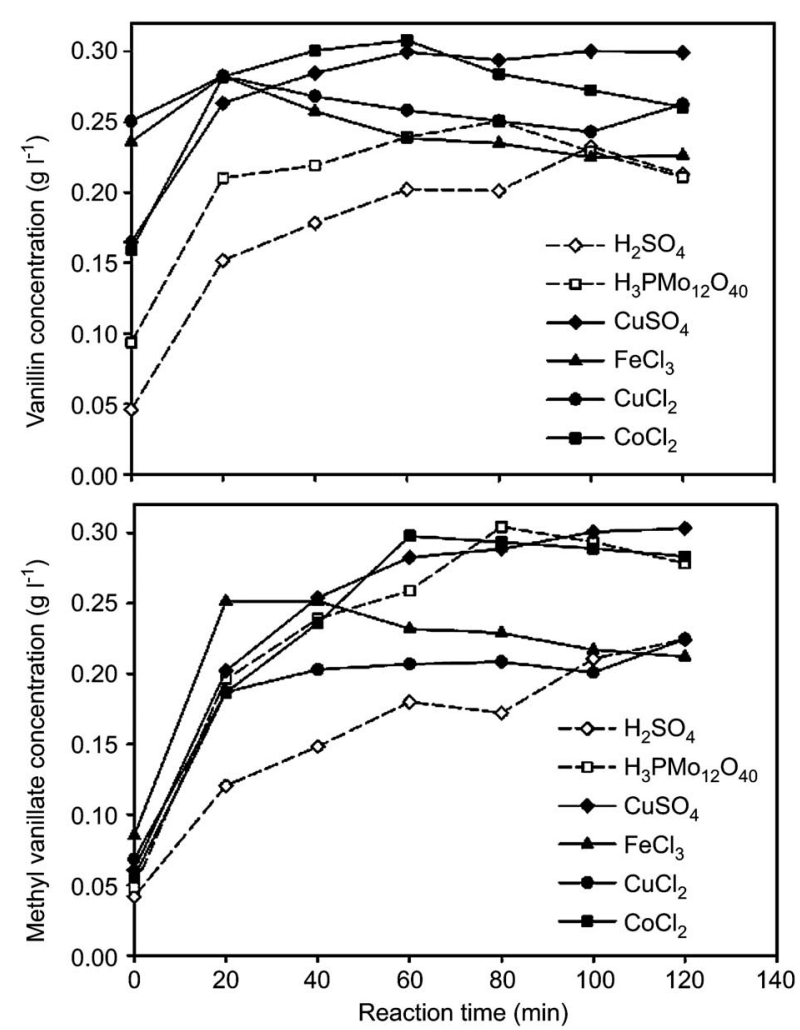

Figure 1 Concentration of vanillin and methyl vanillate versus reaction time for different homogeneous catalysts ( $t=0 \mathrm{~min}$ corresponds to time when reactor has reached the reaction temperature).

The FTIR instrument used was a Spectrum BX (PerkinElmer AG, Schwerzenbach, Switzerland). For each spectrum 64 scans in the range of 600 and $4000 \mathrm{~cm}^{-1}$ (resolution of $2 \mathrm{~cm}^{-1}$ ) were averaged. Band assignment and sample preparation were done according to Faix (1992). The peaks are normalized to the aromatic skeletal vibrations at a wavelength of $1514 \mathrm{~cm}^{-1}$, assuming no significant change in the number of aromatic rings during depolymerization.

\section{Results}

\section{Concentration of low molecular weight products}

Figure 1 shows the concentration of the targeted products (vanillin and methyl vanillate) versus reaction time up to $2 \mathrm{~h}$. Reaction time $t=0$ min means the time when the temperature has reached the reaction temperature of $170^{\circ} \mathrm{C}$. Accordingly, transition metal salts as catalysts enhanced the formation of monomeric products. For all of the studied salts, the concentration maximum of vanillin was higher than without catalyst (sulfuric acid) or in presence of $\mathrm{H}_{3} \mathrm{PMo}_{12} \mathrm{O}_{40}$. As for methyl vanillate, the concentration reached the same level as the studied POM only in experiments with $\mathrm{CoCl}_{2}$ and $\mathrm{CuSO}_{4}$, but its yield was always at least as high as without catalyst. The chloride salts $\mathrm{FeCl}_{3}$ and $\mathrm{CuCl}_{2}$ show, on the other hand, a fast kinetics in the formation of the two products. The highest vanillin yield at time $t=0 \mathrm{~min}$ and a concentration maximum after $20 \mathrm{~min}$ reaction time were obtained with the latter mentioned catalysts, while with the other catalysts, a maximum was not observed before $60 \mathrm{~min}$. The maximum yields of vanillin and methyl vanillate are summarized in Table 1 . To evaluate the progress of the reaction after $2 \mathrm{~h}$, experiments without catalyst and with POM were conducted for $6 \mathrm{~h}$. While the yield remained approximately constant for sulfuric acid, reaching a slightly elevated maximum after $5 \mathrm{~h}$ (vanillin $2.46 \%$, methyl vanillate $2.72 \%$ ), no yield increments were obtained with POM (the yield began to decrease after $2 \mathrm{~h}$ ).

Several other peaks appeared in considerable amounts in the GC/MS chromatogram with transition metal salt catalysts (Figure 2). The compound with a retention time (RT) of 22.75 min was identified to be methyl dehydroabietate (MDHA). It is formed from abietic acid by dehydrogenation and esterification with methanol, as described by Hjulström et al. (2006). Abietic acid is a major constituent of pine resin and bound to the lignin molecule via ester bonds (Shadkami

Table 1 Maximum yields of targeted monomeric products and relative amount of other products within investigated reaction time for the different catalysts.

\begin{tabular}{|c|c|c|c|c|c|c|c|c|}
\hline \multirow[b]{2}{*}{ Compound } & \multicolumn{8}{|c|}{ Peaks in GC/MS as shown in Figure 2} \\
\hline & Vanillin & $\begin{array}{c}\text { Methyl } \\
\text { vanillate }\end{array}$ & a & $\mathrm{b}$ & $\mathrm{c}$ & $\mathrm{d}$ & MDHA & e \\
\hline $\mathrm{RT}$ in $\mathrm{GC} / \mathrm{MS}(\mathrm{min})$ & 12.66 & 14.23 & 17.01 & 18.32 & 18.51 & 22.09 & 22.75 & 23.20 \\
\hline \multirow[t]{2}{*}{$\underline{\mathrm{M}_{\mathrm{w}}\left(\mathrm{g} \mathrm{mol}^{-1}\right)}$} & 152 & 182 & 210 & 240 & 240 & 292 & 314 & 322 \\
\hline & \multicolumn{2}{|c|}{ Maximum yield (by wt) } & \multicolumn{6}{|c|}{ Rel.\%, based on peak area in GC/MS at $t=120 \mathrm{~min}^{a}$} \\
\hline Catalyst & $\begin{array}{c}\text { Vanillin } \\
(\%)\end{array}$ & $\begin{array}{c}\text { Methyl } \\
\text { vanillate }(\%)\end{array}$ & $a(\%)$ & $b(\%)$ & $c(\%)$ & $d(\%)$ & MDHA (\%) & $e(\%)$ \\
\hline None $\left(\mathrm{H}_{2} \mathrm{SO}_{4}\right)$ & 2.41 & 2.33 & 5.2 & 4.9 & 12.1 & 0.0 & 136.1 & 0.9 \\
\hline $\mathrm{H}_{3} \mathrm{PMo}_{12} \mathrm{O}_{40}$ & 2.60 & 3.15 & 8.0 & 19.6 & 28.3 & 1.9 & 110.3 & 6.2 \\
\hline $\mathrm{CuSO}_{4}$ & 3.12 & 3.15 & 30.3 & 53.8 & 52.1 & 13.8 & 95.2 & 18.4 \\
\hline $\mathrm{CoCl}_{2}$ & 3.19 & 3.09 & 36.5 & 66.3 & 70.4 & 17.1 & 102.1 & 22.9 \\
\hline $\mathrm{FeCl}_{3}$ & 2.93 & 2.61 & 81.7 & 137.1 & 80.5 & 30.4 & 101.5 & 37.4 \\
\hline $\mathrm{CuCl}_{2}$ & 2.93 & 2.33 & 103.3 & 157.2 & 85.1 & 54.5 & 107.4 & 55.3 \\
\hline
\end{tabular}

${ }^{a}$ Data in italics are related to the internal standard (syringaldehyde).

GC/MS, gas chromatography/mass spectrometry; RT, retention time; $\mathrm{M}_{\mathrm{w}}$, molecular weight; MDHA, methyl dehydroabietate. 


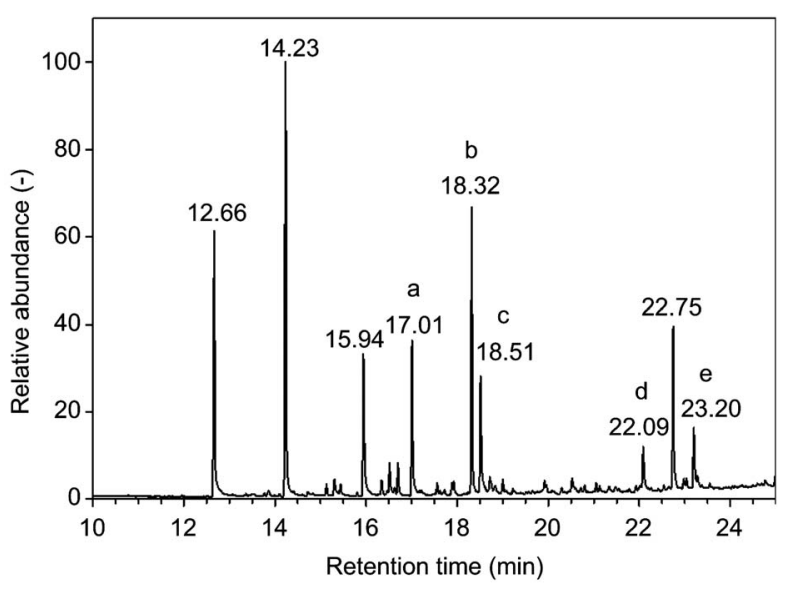

Figure 2 Gas chromatography (GC) chromatogram of extracted products from an experiment with copper chloride after $120 \mathrm{~min}$ of reaction time. The numbers indicate the GC retention time of the adjacent peaks. Peak assignments are in Table 1; the peak at $15.94 \mathrm{~min}$ is the internal standard.

and Helleur 2009). For the compounds with RTs of 17.01, $18.32,18.51,22.09$, and 23.20 min (labeled a-e), the structures could not be identified by MS spectra. Based on the data obtained by HPLC-APCI-MS ${ }^{n}$, however, the structures presented in Figure 3 can be postulated. Nevertheless, isomeric structures of these are also possible. In particular, compounds $b$ and $c$ were found to be isomers. Since small amounts of a and $d$ are obtained in experiments with pure vanillin as substrate, they are direct oxidation products of vanillin. The same is true for the other compounds with methyl vanillate as substrate. Thus, all of the mentioned products are at least partly generated by oxidation of the targeted monomers vanillin and methyl vanillate and therefore are jointly responsible for the yield decrement of the targeted products with proceeding reaction time. The formation of all those compounds, including MDHA, versus time is roughly linear and the maximum amount was therefore usually found at the end of the reaction. The quantitative data are listed in Table 1 (peak areas relative to that of IS).

The amount of MDHA (Table 1) at the end of the reaction did not vary significantly between the experiments with dif-

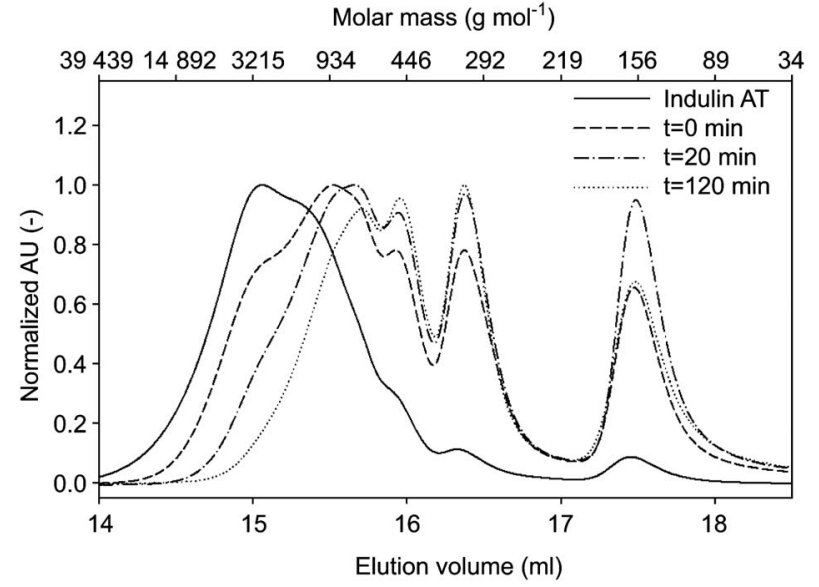

Figure 4 Size-exclusion chromatography characterization of different samples from an experiment with iron chloride catalyst compared to Indulin AT.

ferent catalysts. However, more MDHA was obtained in the absence of any additional catalyst. This was not the case for the compounds a-e. While their formation without catalyst was rather negligible, in presence of $\mathrm{FeCl}_{3}$ and $\mathrm{CuCl}_{2}$ the yields of the substances a-e increased dramatically.

\section{Weight-average molecular weight $\left(M_{w}\right)$}

The molecular weight distribution (MWD) was monitored versus reaction time by SEC as for the iron chloride experiment in Figure 4. The plots of $\mathrm{M}_{\mathrm{w}}$ against reaction time for each experiment are depicted in Figure 5. For Indulin AT the SEC method revealed an $M_{w}$ of approximately $3500 \pm$ $300 \mathrm{~g} \mathrm{~mol}^{-1}$, which is in very good agreement with literature values (Jacobs and Dahlman 2000). When working without catalyst (only $\mathrm{H}_{2} \mathrm{SO}_{4}$ ), the depolymerization proceeded very slowly. Even with POM as catalyst, the decrease in the $M_{w}$ was only slightly enhanced. A far better fragmentation was achieved with transition metal salts. The $\mathrm{M}_{\mathrm{w}}$ of the product mixture was considerably lower for all of the salts and decreased to approximately $500 \mathrm{~g} \mathrm{~mol}^{-1}$ at the end of the reaction with $\mathrm{FeCl}_{3}$ or $\mathrm{CuCl}_{2}$.<smiles>COC(=O)c1cc(C=O)cc(OC)c1O</smiles>

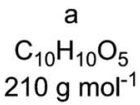
$210 \mathrm{~g} \mathrm{~mol}^{-1}$<smiles>COC(=O)c1cc(OC)c(O)c(C(=O)OC)c1</smiles>

b, c $\mathrm{C}_{11} \mathrm{H}_{12} \mathrm{O}_{6}$ $240 \mathrm{~g} \mathrm{~mol}^{-1}$<smiles>COC(=O)C1CC(=O)c2c(C=O)cc(OC)c(O)c2C1=O</smiles>

d $\mathrm{C}_{14} \mathrm{H}_{12} \mathrm{O}_{7}$ $292 \mathrm{~g} \mathrm{~mol}^{-1}$<smiles>COC(=O)c1cc(OC)c(O)c2c1C(=O)C(C(=O)OC)CC2=O</smiles>
e<smiles>[18OH]c1ccccc1</smiles>
$322 \mathrm{~g} \mathrm{~mol}^{-1}$

Figure 3 Postulated structures for the components of peaks a-e in the chromatogram as derived from HPLC-APCI-MS ${ }^{\mathrm{n}}$ analysis. Compounds $\mathrm{b}$ and $\mathrm{c}$ are isomers. 


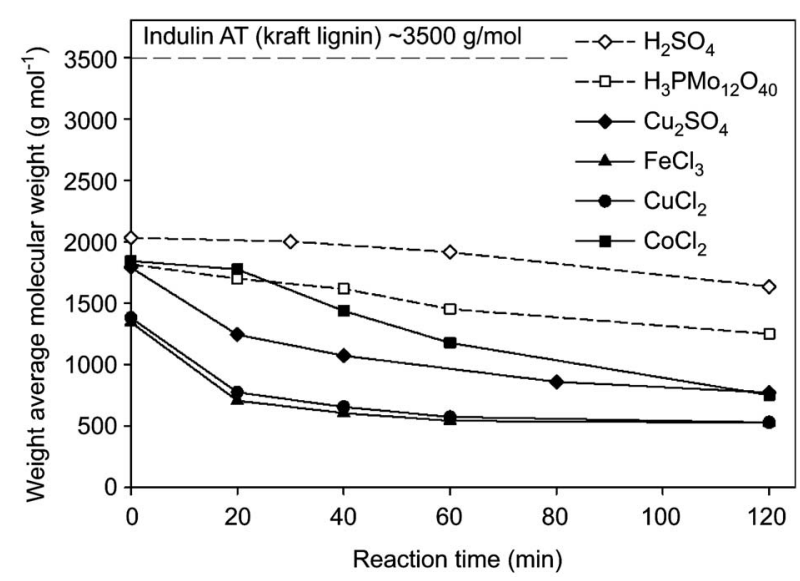

Figure 5 Weight-average molecular weight of the product mixture versus reaction time for different homogeneous catalysts.

\section{Oxygen consumption}

For evaluating the action of the different catalysts concerning the oxidation, the consumption of oxygen was analyzed by comparing both FTIR spectra of the reaction products and the loss of pressure in the reactor during the reaction. Reaction products of experiments without catalyst and with $\mathrm{CuCl}_{2}$ were extracted with $\mathrm{CHCl}_{3}$ and FTIR spectra of the extracts were recorded. In Figure 6, the spectra can be compared to Indulin AT in the region between 850 and $1950 \mathrm{~cm}^{-1}$. The most important difference between the spectra is in the range between 1600 and $1800 \mathrm{~cm}^{-1}(\mathrm{C}=\mathrm{O}$ bonds). After treatment with sulfuric acid, the band areas in this region increased, indicating a higher amount of $\mathrm{C}=\mathrm{O}$ compared to Indulin AT. The analysis of products from experiments with $\mathrm{CuCl}_{2}$ show further increased band areas and therefore an even higher oxygen consumption. An estimation of the $\mathrm{C}=\mathrm{O}$ content of the samples according to Faix et al. (1998) resulted in $3.6 \%$ (23.6 $\mathrm{C}=\mathrm{O}$ per $100 \mathrm{C}_{9}$ ) for Indulin, $5.8 \%\left(35.8 \mathrm{CO} / \mathrm{C}_{900}\right)$ for sulfuric acid, and $7.2 \%\left(43.6 \mathrm{CO} / \mathrm{C}_{900}\right)$ for $\mathrm{CuCl}_{2}$. As no significant change in the amount of hydroxyl groups (3412$3460 \mathrm{~cm}^{-1}$ ) was observed, the formation of $\mathrm{C}=\mathrm{O}$ linkages seems not to arise from direct oxidation of aliphatic hydroxyl groups. More likely, $\mathrm{C}=\mathrm{O}$ formation is due either to cleavage of linkages in acidic media in the presence of oxygen, as described by Gierer and Nilvebrant (1994), or to oxidation of vanillin and methyl vanillate as mentioned above.

A comparison of pressures after cooling down the reactor at the end of the reaction gives similar results (Table 2). Although these observation cannot give absolute values (liquid samples are withdrawn during the reaction changing the gas volume, and small amounts of $\mathrm{CO}_{2}$ and dimethyl ether are formed during the reaction), a clear trend is observed. Only small amounts of oxygen are consumed in the experiments without catalyst and with POM. In contrast, in the transition metal salt experiments the far lower pressures at the end of the reaction reveal considerably higher oxygen consumption. Moreover, the remaining pressure at the end of the reaction seems to correlate with the $\mathrm{M}_{\mathrm{w}}$ at a reaction time of $120 \mathrm{~min}$ (Table 2). The experiment without catalyst con-

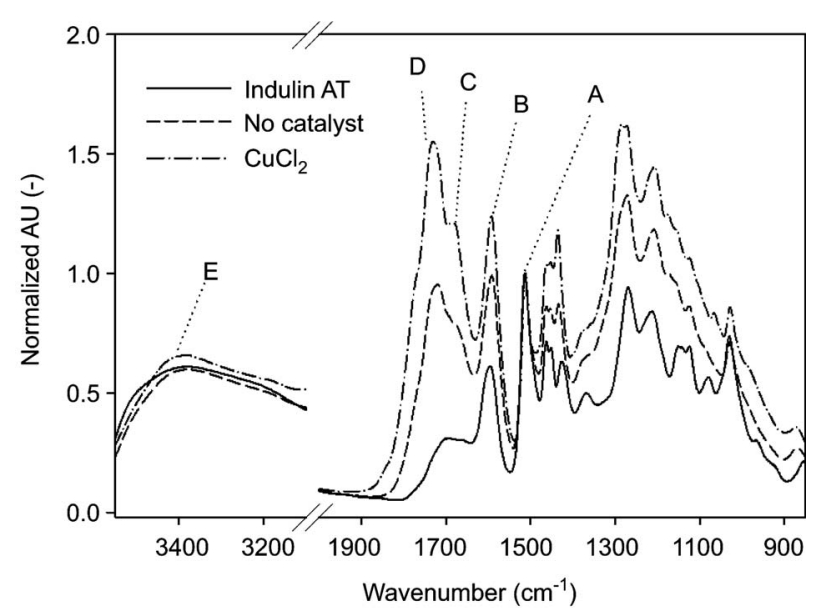

Figure 6 Fourier transform infrared spectroscopy (FTIR) spectra of extracted products from experiments with $\mathrm{CuCl}_{2}$ catalyst and without catalyst in comparison with the FTIR spectrum of Indulin AT. The labeled peaks show the region of IR absorbance of: (A) aromatic skeletal vibrations $\left(1514 \mathrm{~cm}^{-1}\right)$, (B) aromatic skeletal vibrations plus $\mathrm{C}=\mathrm{O}$ stretch $\left(1593 \mathrm{~cm}^{-1}\right),(\mathrm{C}) \mathrm{C}=\mathrm{O}$ stretch of conjugated aldehydes and carboxylic acids $\left(1680 \mathrm{~cm}^{-1}\right)$, (D) $\mathrm{C}=\mathrm{O}$ stretch in unconjugated ketones, carbonyls, and ester groups $\left(1732 \mathrm{~cm}^{-1}\right)$, and (E) O-H stretch $\left(3412-3460 \mathrm{~cm}^{-1}\right)$.

sumed the least amount of oxygen and the $\mathrm{M}_{\mathrm{w}}$ was the highest, and vice versa for the experiments with $\mathrm{CuCl}_{2}$ or iron $\mathrm{FeCl}_{3}$. A linear regression of the remaining pressure and the $M_{w}$ resulted in a good correlation $\left(R^{2}=0.95\right.$, results not shown). By calculating the initial $\mathrm{M}_{\mathrm{w}}$ of Indulin AT based on this correlation (extrapolation to 10 bar initial oxygen pressure) a value of $3946.5 \mathrm{~g} \mathrm{~mol}^{-1}$ was obtained.

\section{Variation of catalyst amount}

Based on the results described above, catalyst concentration experiments were performed with $\mathrm{CuCl}_{2}$ in the range between 0.005 and $0.05 \mathrm{~mol} \mathrm{l}^{-1}$. At the concentration of $0.05 \mathrm{~mol} \mathrm{l}^{-1}$, the experiment was stopped after $20 \mathrm{~min}$ reaction time because of corrosion problems of the stirrer bearings in the presence of high chloride concentrations.

Figure 7 shows the concentrations of vanillin and methyl vanillate as a function of reaction time and $\mathrm{CuCl}_{2}$ concentration. While the vanillin concentration is comparable between experiments with 0.005 and $0.01 \mathrm{~mol} \mathrm{l}^{-1}$ of catalyst,

Table 2 Final pressure in the reactor and average molecular weight for the different catalysts.

\begin{tabular}{lcc}
\hline \multicolumn{1}{c}{ Catalyst } & $\begin{array}{c}\text { Pressure } \\
\text { (bar) }\end{array}$ & $\begin{array}{c}\mathrm{M}_{\mathrm{w}} \text { at } t=120 \mathrm{~min} \\
\left(\mathrm{gmol}^{-1}\right)\end{array}$ \\
\hline None $\left(\mathrm{H}_{2} \mathrm{SO}_{4}\right)$ & 5.6 & 1636 \\
$\mathrm{H}_{3} \mathrm{PMo}_{12} \mathrm{O}_{40}$ & 5.4 & 1250 \\
$\mathrm{CuSO}_{4}$ & 4.2 & 775 \\
$\mathrm{CoCl}_{2}$ & 4.4 & 753 \\
$\mathrm{FeCl}_{3}$ & 3.7 & 529 \\
$\mathrm{CuCl}_{2}$ & 3.8 & 531 \\
\hline
\end{tabular}

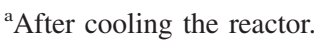



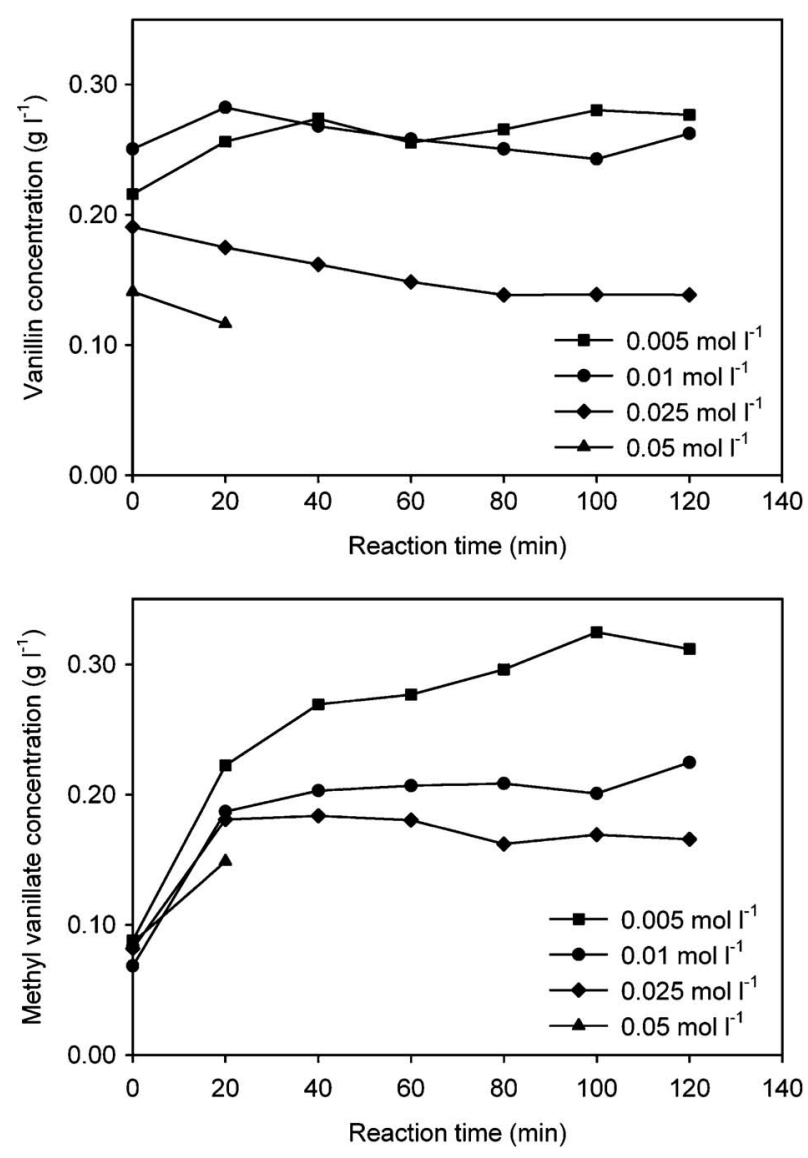

Figure 7 Concentration of vanillin and methyl vanillate versus reaction time for different concentrations of copper chloride.

a higher concentration results in a decrease of vanillin yield after the beginning of the reaction time $(t=0 \mathrm{~min})$ and the yield is further lowering toward the end of the reaction time. The occurrence of a maximum can be assumed during the heating time. However, this effect is not observed for methyl vanillate. Although a higher catalyst concentration decreases the product concentration as well, a rather constant level is reached without a pronounced maximum. Concerning the products a-e, an increase in product formation with increasing amount of $\mathrm{CuCl}_{2}$ is found. This is consistent with the lower amount of vanillin and methyl vanillate as their oxidation led to the formation of a-e, which is apparently enhanced for higher amounts of catalyst.

The change in $\mathrm{M}_{\mathrm{w}}$ as a function of catalyst concentrations is presented in Figure 8. As expected, the fastest fragmentation kinetics is obtained for a catalyst concentration of $0.05 \mathrm{~mol} \mathrm{l}^{-1}$, which results in an average molecular weight of $386 \mathrm{~g} \mathrm{~mol}^{-1}$ after only $20 \mathrm{~min}$ reaction time. Decreasing the amount of $\mathrm{CuCl}_{2}$ results in a higher final molecular weight, whereas no significant difference is observable once again for the two lowest concentrations of 0.01 and $0.005 \mathrm{~mol} \mathrm{l}^{-1}$.

\section{Discussion and conclusions}

In general, the selectivity of the studied transition metal salt catalysts towards the monomeric products vanillin and meth- yl vanillate was only slightly enhanced. The maximum yield of vanillin obtained in the experiments was always higher for the transition metal salts than for the POM or without a catalyst. However, the oxidation of vanillin and methyl vanillate to yield compounds a-e led to decreasing concentrations with proceeding reaction time. For vanillin this was even emphasized at higher levels of catalyst.

$\mathrm{CoCl}_{2}$ turned out to be the best of the investigated catalysts regarding the total yield of vanillin and methyl vanillate, with a maximum yield of $6.3 \%$ after 60 min of reaction time. Furthermore, methyl dehydroabietate was found as product in all samples and, especially with $\mathrm{FeCl}_{3}$ of $\mathrm{CuCl}_{2}$ as catalyst, five additional products of low molecular weight were obtained in significant amounts. The formation kinetics of vanillin and methyl vanillate was also enhanced by using those catalysts, as they showed the highest yield at the start of the reaction time and the maximum was already obtained in an early stage of the reaction. The fast kinetics is also shown by the rapid decrease in the mean molecular weight down to $500 \mathrm{~g} \mathrm{~mol}^{-1}$ and the enhanced oxygen consumption as shown by FTIR. When increasing the amount of $\mathrm{CuCl}_{2}$, the maximum concentration was even shifted to the range of heating time and the fragmentation kinetics was further enhanced.

Among the different chlorides, cobalt chloride yielded most of the targeted products but was not very efficient in the depolymerization of the lignin molecule compared to iron chloride or copper chloride. This might be due to the lower redox potential of cobalt. On the other hand, since iron and copper led to comparable results concerning product yield and fragmentation, the fragmentation seems not to be limited by the redox potential of the catalyst when working above a certain redox potential. However, the fact that copper chloride and copper sulfate showed different results proves that the catalytic action can be ascribed to both cation and anion, rather than to the cation alone. For a detailed understanding of the catalytic action of the catalyst additional studies are necessary.

Experiments focusing on the reactor heat-up phase have revealed that much of the lignin oxidation already takes place

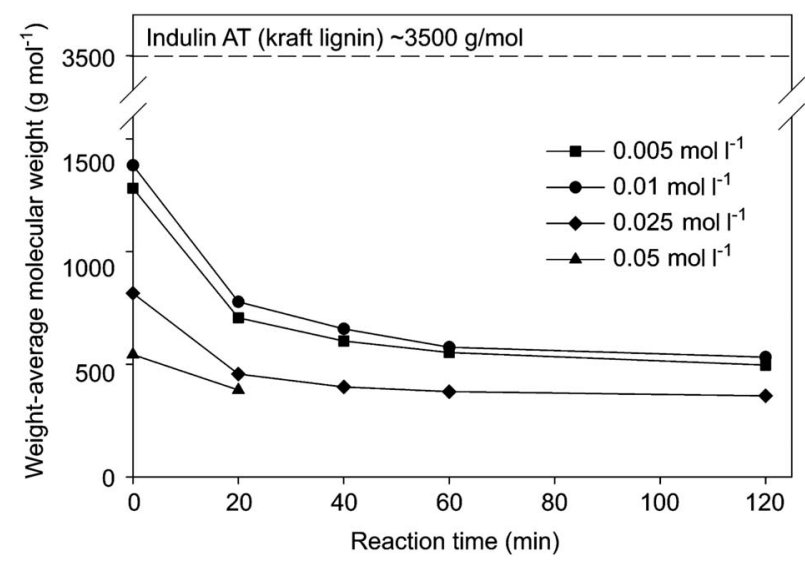

Figure 8 Weight-average molecular weight of the product mixture versus reaction time for different concentrations of copper chloride. 
before reaching the targeted reaction temperature. Therefore, upcoming investigations will focus on the oxidation of lignin in a continuous reactor with preheating of separated feed streams. In addition, the present results regarding oxygen consumption show that most of the oxygen had already been used up at the end of some experiments. Future experiments with a constant oxygen pressure in the reactor will ensure identical conditions during the reaction.

\section{Acknowledgements}

The authors would like to thank the Commission of Technology and Invention (CTI) of the Swiss Federal Office of Professional Education and Technology (OPET) for financial support of this research. In addition, we would like to thank Karl Fluri from Sika Technology AG for performing HPLC-APCI-MS ${ }^{\mathrm{n}}$ analysis.

\section{References}

Amen-Chen, C., Pakdel, H., Roy, C. (2001) Production of monomeric phenols by thermochemical conversion of biomass: a review. Bioresour. Technol. 79:277-299.

Beis, S.H., Mukkamala, S., Hill, N., Joseph, J., Baker, C., Jensen, B., Stemmler, E.A., Wheeler, M.C., Frederick, B.G., van Heiningen, A., Berg, A.G., DeSisto, W.J. (2010) Fast pyrolysis of lignins. BioResources 5:1408-1424.

Faith, W.L., Keyes, D.B., Clark, R.L. (1965) Vanillin. In: Industrial Chemicals. John Wiley \& Sons, New York. pp. 796-799.

Faix, O. (1992) Fourier transform infrared spectroscopy of lignin in solid state. In: Methods in Lignin Chemistry. Eds. Lin, S.Y., Dence, C.W. Springer, Berlin. pp. 83-109.

Faix, O., Andersons, B., Zakis, G. (1998) Determination of carbonyl groups of six round robin lignins by modified oximation and FTIR spectroscopy. Holzforschung 52:268-274.

Ferraz, A., Souza, J.A., Silva, F.T., Goncalves, A.R., Bruns, R.E., Cotrim, A.R., Wilkins, R.M. (1997) Controlled release of 2,4-D from granule matrix formulations based on six lignins. J. Agric. Food Chem. 45:1001-1005.

Gaspar, A.R., Gamelas, J.A.F., Evtuguin, D.V., Pascoal Neto, C. (2007) Alternatives for lignocellulosic pulp delignification using polyoxometalates and oxygen: a review. Green Chem. 9:717730.

Gierer, J., Nilvebrant, N.O. (1994) Studies on the degradation of lignins by oxygen in acidic media. Holzforschung 48(Suppl.): 51-58.

Goheen, D.W. (1981) Chemicals from lignin. In: Organic Chemicals from Biomass. CRC Press, Boca Raton, FL. pp. 143-162.
Hermans, I., Spier, E., Neuenschwander, U., Turrà, N., Baiker, A. (2009) Selective oxidation catalysis: opportunities and challenges. Top. Catal. 52:1162-1174.

Hjulström, B., Isaksson, S., Hennius, A. (2006) Organic geochemical evidence for pine tar production in middle eastern Sweden during the Roman Iron Age. J. Archaeol. Sci. 33:283-294.

Hocking, M.B. (1997) Vanillin: synthetic flavoring from spent sulfite liquor. J. Chem. Educ. 74:1055-1059.

Jacobs, A., Dahlman, O. (2000) Absolute molar mass of lignins by size exclusion chromatography and MALDI-TOF mass spectroscopy. Nord. Pulp Pap. Res. J. 15:121-127.

Olsson, M.R., Axelsson, E., Berntsson, T. (2006) Exporting lignin or power from heat-integrated kraft pulp mills: a techno-economic comparison using model mills. Nord. Pulp Pap. Res. J. 21:476-484.

Partenheimer, W. (2009) The aerobic oxidative cleavage of lignin to produce hydroxyaromatic benzaldehydes and carboxylic acids via metal/bromide catalysts in acetic acid/water mixtures. Adv. Synth. Catal. 351:456-466.

Pye, E.K. (2008) Industrial lignin production and applications. In: Biorefineries - Industrial Processes and Products. Eds. Kamm, B., Gruber, P.R., Kamm, M. Wiley-VCH, Weinheim. pp. 165200.

Shadkami, F., Helleur, R. (2009) Use of an injection port for thermochemolysis-gas chromatography/mass spectrometry: rapid profiling of biomaterials. J. Chromatogr. A 1216:5903-5910.

Tomani, P., Axegard, P. (2007) Development and demonstration of the LignoBoost process. In: The ILI Umbrella Programme and Other Existing and New Approaches in Lignin Research. ILI 8th Forum, Rome, Italy. International Lignin Institute, Lausanne. pp. 109-113.

Villar, J.C., Caperos, A., García-Ochoa, F. (2001) Oxidation of hardwood kraft-lignin to phenolic derivatives with oxygen as oxidant. Wood Sci. Technol. 35:245-255.

Voitl, T., Rudolf von Rohr, P. (2008) Oxidation of lignin using aqueous polyoxometalates in the presence of alcohols. ChemSusChem. 1:763-769.

Voitl, T., Nagel, M.V., Rudolf von Rohr, P. (2009) Analysis of products from the oxidation of technical lignins by oxygen and $\mathrm{H}_{3} \mathrm{PMo}_{12} \mathrm{O}_{40}$ in water and aqueous methanol by size-exclusion chromatography. Holzforschung 64:13-19.

Wu, G., Heitz, M., Chornet, E. (1994) Improved alkaline oxidation process for the production of aldehydes (vanillin and syringaldehyde) from steam-explosion hardwood lignin. Ind. Eng. Chem. Res. 33:718-723.

Zakzeski, J., Bruijnincx, P.C.A., Jongerius, A.L., Weckhuysen, B.M. (2010) The catalytic valorization of lignin for the production of renewable chemicals. Chem. Rev. 110:3552-3599.

Received November 21, 2010. Accepted March 2, 2011.

Previously published online May 20, 2011. 